\title{
Public leadership and participation: understanding the experiences of South African local government officials' engagement within informal settlements in the Western Cape
}

\author{
Elmé Vivier, Derick de Jongh and Lisa Thompson
}

The Version of Record of this manuscript has been published and is available in Public Management Review, 14 May 2020, DOI: 10.1080/14719037.2020.1764082

\begin{abstract}
Studies of public leadership increasingly recognize the importance of collaboration as a mechanism for delivering public policy. Despite theoretical and empirical developments in this direction, insufficient attention has been given to developing country contexts. The literature is also analytically superficial with regard to the involvement of citizens and communities. This article uses qualitative evidence from a South African Western Cape municipality to explore how officials engage informal settlements in service delivery. The article discusses how officials mobilize communities, navigate relations, and frame agendas for the purposes of public engagement. This provides an entry to understand officials' practices and leadership influence.
\end{abstract}

Keywords: Public leadership, collaboration, community participation, local government, South Africa

\section{Introduction}

Collaborative contexts reflect changing forms of governance away from traditional hierarchical bureaucracies (in the classic Weberian sense), towards networks and partnerships (Morse 2010). Where authority, knowledge and resources are dispersed across sectors, organisations and geographic scales (Sullivan et al. 2012), public, private and civic actors must work together to solve complex problems and deliver services. 
Such contexts raise important questions for the practice of leadership, and particular the role of public officials who may be expected to initiate and lead such endeavours. This leadership role involves, inter alia: convening multiple stakeholders (Vangen, Hayes and Cornforth 2015); navigating competing interests (Sullivan et al. 2012); managing power disparities (Page 2010); building relational bonds (Ospina and Foldy 2010); and generating common purpose (Crosby and Bryson 2005). These are not necessarily distinct tasks, but together permeate the process of enabling and sustaining collaborative action.

Although studies of public leadership increasingly focus on contexts of interorganisational and cross-sectoral collaboration (Chapman et al. 2015; Orazi et al. 2013; Van Wart 2013; Vogel and Masal 2015), according to Sullivan et al. (2012), research in this direction remains limited. This article contributes to this field by exploring the engagement of citizens and communities in local governance, rather than collaboration between formal organisations (Armistead et al. 2007), as reflected in collaborative governance and collaborative public management literatures (Ospina 2017). With a few exceptions (see for instance, Bono, Shen and Snyder 2010; Feldman et al. 2006; Page 2010; Van Wart 2013; Vogel and Masal 2015), citizen/community engagement remains an under-researched area (Bono et al. 2010). And yet, as noted by Van Wart (2013), the inclusion of poor and marginalized citizens is particularly crucial for addressing power imbalances in collaboration. There are also few studies of public leadership in collaboration situated in developing country contexts (Raffel et al. 2009; Vogel and Masal 2015).

This article contributes to this literature by examining collaboration between officials and informal settlement communities in a South African municipality. Drawing on qualitative data from interviews and focus groups with 59 municipal officials as part 
of the lead author's doctoral research, the article explores how officials mobilize communities, navigate relations between different actors, and frame agendas across a variety of project and service delivery processes. Through a social constructionist lens, we consider how officials exercise their leader agency through these practices, and thereby fulfil their leadership roles.

We begin with a review of how the public leadership literature understands the purpose and challenges of cross-sector collaboration, and identify three practices often ascribed to leaders and deemed important for collaborative success. We then situate the article in the South African municipal context, where officials are mandated to engage citizens and communities in their project and service delivery work, especially in informal settlements. Combining the framework of the three leadership practices with a social constructionist lens, we abductively analyze how officials mobilize communities, navigate relations and frame agendas. The data show that in undertaking these practices, officials respond to community contexts and inputs, but do so in the service of project delivery goals and within the scope allowed by government priorities and governance systems. On this basis, we suggest officials' practices involve leadership agency insofar as they adapt formal policies and mechanisms to local realities, but they also remain situated within structural constraints that limit the scope of their leadership influence to specific participatory initiatives.

\section{Public leadership in collaboration: challenges, approaches and practices}

Theorizations of public leadership define it as 'leadership for the common good' focused on tackling 'public problems' in a 'shared-power world' (Crosby and Bryson 2005). It is not surprising then that collaboration has emerged as an important area of research in the field of public leadership (Chapman et al. 2015; Crosby and Bryson 2005; Morse 2010; Orazi et al. 2013; Van Wart 2013; Vogel and Masal 2015). Studies 
of cross-sectoral collaboration reflect shifts in governance modalities, away from hierarchical to more 'networked' forms of service provision (Cepiku and Masrodascio 2019; Vangen et al. 2015). Collaboration in this context may refer to contract-based outsourcing as a mechanism for service delivery (Kellis and Ran 2013), or to the involvement of stakeholders in deliberative decision-making (Ansell and Gash 2007). It could take the form of inter-agency, public-private, or public-civic partnerships (Ollerenshaw, Murphy and McDonald 2017; Uster, Beeri and Vashdi 2018). Receiving less attention are forms of collaboration involving citizens and communities directly (Bono et al. 2010).

It is often public officials or administrators who are expected to initiate and lead collaborations (Dacombe 2011; Sørensen and Torfing 2019; Vangen et al. 2015). As noted in the introduction, this involves, inter alia, bringing together actors and organisations with diverse interests and resources, building relationships, managing conflicts and facilitating deliberative decision-making towards agreement. Yet, fulfilling these tasks can be challenging.

For one, the diversity of interests and expectations invariably creates tension and conflict (Sullivan et al. 2012). Efforts to balance competing concerns may be thwarted by lack of trust and incomplete information (Vangen et al. 2015). There may also be ambiguity about the membership of the collaboration, or difficulties in specifying aims, making it difficult to build consensus (Armistead et al. 2007). Bussu and Galanti (2018) point to potential tensions between the visions of citizens, who may desire greater control over public resources and services, and those of government actors interested in increasing efficiencies and reducing costs. Failure to produce a 'shared vision' can also jeopardize the process overall. Further, public officials are expected to 'lead a group of peers' both inside and outside the organization, through a kind of 'horizontal leadership' 
where traditional forms of authority are irrelevant (Torfing et al. 2019, 815). However, for public officials, collaboration still takes place within a bureaucracy where it can be difficult to manoeuvre and respond to changing circumstances (Connelly 2007; Wallace et al. 2011).

Despite these challenges, a number of studies (e.g. Crosby and Bryson 2010; Huxham and Vangen 2005; Ospina and Foldy 2010; Page 2010) identify crucial leadership practices that shape collaboration, with the potential of achieving consensus and commitment to addressing shared problems. In the next section, we examine these practices as part of a social constructionist approach to understanding leadership.

\section{A social constructionist approach to public leadership}

Studies of public leadership include both leader-centric and social constructionist approaches (Chapman et al. 2015; Lawler 2008; Vogel and Masal 2015), although some scholars (e.g. Morse 2010; Raffel et al. 2009; Tourish and Barge 2010) argue the latter is more suitable for explaining leadership influence in contexts of collaborative ambiguity and complexity. From a social constructionist perspective, leadership is viewed as a social phenomenon emerging in contextually specific ways (Ospina 2017). Rather than defining or categorizing what leadership is, this approach raises different questions about leadership (Collinson 2014; Knights and Willmott 1992), such as: 'how do leaders manage collaborations to make things happen?' (Ospina and Saz-Carranza 2010, 425), or: 'what mechanisms lead collaborative activity and outcomes in one direction rather than another?' (Vangen and Huxham 2003, S62). The objective is therefore to gain insight into the dynamic social relations, processes and practices producing leadership (Carroll et al. 2008; Drath 2008; Hosking 2011).

This does not preclude the importance of individual leader agency, however. Sullivan et al. $(2012,58)$, for instance, refer to the recursive relationship 'between 
structure, agency and ideas' in producing leadership influence. Huxham and Vangen (2005) similarly theorize leadership as the dynamic influence between structures, processes and participants, and show how the design of a collaboration influences interactions and agency within. Crosby and Bryson (2005) explore leadership agency at multiple levels (personal, team, organisational and societal), alongside the settings (forums and arenas) of action. In line with these approaches, we agree with Uhl-Bien (2006) that one need not produce a strict dichotomy between agency and structure, but rather that these enable different aspects of a phenomenon to come to light.

In this article, we focus on leadership practices (Fairhurst and Grant 2010; Ospina and Foldy 2010; Raelin 2016) as an entry point for exploring what individual leaders do or are expected to do, as well as the broader patterns of social activity comprising the context for individual actions (Rouse 2007). This practice lens is evident in the public leadership literature, especially where it pertains to the work of officials in collaborative contexts.

\section{Three public leadership practices}

In a review of the literature, we identified three practices that reflect the core challenges of collaboration, as well as the potential to overcome them. Page's (2010) discussion of three broad leadership 'tactics' - framing agendas, convening stakeholders, and structuring deliberations - provide a starting point. Although the contexts are different, Page's (2010) study includes citizen involvement and is therefore closely aligned with the kind of participation we focus on in this article. Given the closely intertwined processes of mobilizing and structuring, these are presented together. The work of Huxham and Vangen (2005) and Crosby and Bryson (2010) have also informed the identification of these practices. In addition, the practice of 'navigating relations' draws particularly on the work of Ospina and Foldy (2010) and Ospina and Saz-Carranza 
(2010). Although they studied leadership in social change organisations, their theoretical framing and analysis resonate with the social constructionist approach of this article.

An important guiding principle in identifying these practices was whether each practice is sufficiently broad to allow for contextual specificities and nuances to emerge. Our aim was to develop a framework for data analysis, whilst ensuring the operationalization of each practice is not overly pre-defined, as cautioned by Crevani et al. (2010). The rest of this section details each of these practices, which forms the basis for the discussion of the South African case.

\section{Mobilizing stakeholders and communities}

Mobilizing practices are the necessary starting point for any engagement. This entails identifying organisations or individuals, encouraging their involvement, and sustaining their commitment (Morse 2010). Decisions about who is 'in' and 'out' influences both the process and outcomes of collaboration (Vangen and Huxham 2003). For Crosby and Bryson $(2010,218)$, stakeholders can be identified based on their technical expertise or specialized knowledge, their authority, or even their 'commitment and enthusiasm'. Leaders must also consider anyone who would like to be involved, especially if they claim to represent a particular group or community (Vangen and Huxham 2003). In addition, mobilizing stakeholders and communities is intertwined with the work of structuring. Decisions about platforms or venues to use can influence who gets involved, how issues and interests are shared, and how decisions are made (Page 2010). Collaborative structures thus link individuals, resources and ideas (Crosby and Bryson 2010), but may also privilege certain interests and capabilities, and either reduce or enhance power disparities (Ansell and Gash 2007; Fung and Wright 2001). 


\section{Navigating relations}

The second practice necessary for collaboration is navigating relations between different stakeholders. This is at the heart of many of the challenges with collaboration. It involves: mediating between competing interests; shaping concerns and identities towards shared understanding (Ospina and Foldy 2010); and acknowledging and preserving differences (Sullivan et al. 2012). The leader does not simply engage 'followers', but facilitates interactions between peers in order to surface and bridge differences and build trust (Mandell and Keast 2009). This may be enacted through a variety of tactics, such as the exchange of information, the delegation of roles to participants, and personalized attention to specific individuals to make them feel personally connected and invited (Ospina and Foldy 2010).

\section{Framing agendas}

The practice of framing agendas speaks to how leaders and collaborators identify and make sense of a particular problems, emphasize a particular perspective, and develop potential solutions (Crosby and Bryson 2010; Page 2010). Framing establishes the purpose, norms and values of the collaboration, with the ultimate aim of achieving a shared vision and commitment to finding appropriate solutions (Hsieh and Liou 2018). The concept of framing agendas resonates with theorisations of leadership as a process of 'meaning-making', and the view of leaders as 'managers of meaning' (Sullivan et al. 2012, 44). Practically, it is often characterized by dialogue and deliberation over specific situations, issues, proposals, programmes or initiatives.

These three practices point to key ways that leaders can shape collaboration and potentially ensure collaborative success. It is within the backdrop of this literature that the article examines how officials in a South African municipality mobilize 
communities, navigate relations, and frame agendas. How do officials influence the participatory process through these practices? And what informs or drives their practices in this context?

\section{Participation in the South African local government context}

The reconfiguration of the South African state post 1994 has centred on transforming the exclusionary political and socio-economic system of apartheid into a democratic and inclusive one. This involves fulfilling the constitutional mandate to engage citizens in local governance and service delivery through formal participatory structures (RSA 1996). It also requires addressing entrenched spatial patterns that had located the black African majority in townships and informal settlements on the urban periphery, and the purposeful neglect of infrastructure and service provision to those areas (von Schnitzler 2008). Defined as makeshift dwellings erected on land either illegally or without official sanction or documentation, and lacking municipal services (HDA 2012), it is often in informal settlements where the service delivery and participation mandates most visibly and practically intersect. Rapid urbanisation further exacerbates service backlogs (Turok and Parnell 2009). Whilst multiple complex challenges, from 'unfunded mandates' to intergovernmental tensions, constrain the ability to deliver (Winkler 2011), the reach of government in informal settlements has historically been limited (Drivdal 2016). This is despite the establishment of numerous structures and processes for participation.

At the local level, the participation mandate has been institutionalized through various prescribed mechanisms that can be organized into three areas of operation: citywide planning and budgeting; formal and ad hoc engagements through political representative structures such as ward councillors and ward committees; and community engagement and representation in development projects and service 
delivery, often through 'project steering committees' (RSA 2000). It is in the latter, based at the department and project level, where officials have a central role in initiating, designing and leading community participation.

Despite this formalisation, formal engagements have largely failed to realize the promises and imperatives for democratic inclusion and development (Heller 2001; Lemanski 2017; Miraftab and Wills 2005; Sinwell 2011). In particular, it appears that participation has been reduced to a routine and formulaic process focused on technical delivery issues, disconnected from actual decision-making, and intended to garner community ‘buy-in' for predetermined decisions (Oldfield 2008; Smith 2011). Furthermore, according to Tapscott and Thompson (2013), there has been little scholarly research into the experiences of officials who are tasked to lead participation (for exceptions, see Smith 2011; Winkler 2011). Most policy formulation occurs at the national level (Winkler 2011), and although certain aspects of participation are prescribed therein, there remains considerable scope and need for officials to adapt such requirements to local contexts (Tapscott and Thompson 2013). This participation mandate imparts a crucial leadership role to officials. How they realize this mandate through key leadership practices in informal settlement contexts, is thus the focus of this article.

\section{Methods}

This article draws on data collected through a qualitative case study of a South African municipality in the Western Cape. A qualitative approach to researching leadership provides an opportunity to simultaneously explore individual experiences and practices as well as broader processes and contextual factors (Bryman 2004). The research comprised in-depth, semi-structured interviews and focus groups with 59 municipal officials. Participants were selected through purposive, snowball and convenience 
sampling, and represent various administrative positions across 13 line and corporate departments. Permission granted by the municipality requires that it remain anonymous. For this reason, it will be referred to as 'the municipality' and discussion of its specific institutional and socio-political context will be limited.

The interviews elicited officials' views on the purpose of participation, their methods, practices, and processes for engaging citizens, and their main challenges. Their narratives provide a lens for understanding the roles and influence of officials as leaders of participation, but also how they are situated in and shaped by the broader context. All interviews were audio recorded and transcribed. The data were analysed abductively (Klag and Langley 2013) through a combination of open and thematic coding (Miles, Huberman and Saldaña 2014) using Atlas.ti.

First, three descriptive a priori codes sorted the data into: (1) views regarding the purpose of participation; (2) key practices used to implement participation; and (3) challenges experienced. These categories were based on the semi-structured interview questionnaire, and were combined with open coding of the data that produced a second layer of codes (see Table 1 below). Open coding was also done at the 'first level' to allow for any emerging themes that did not fit within the three a priori codes. The analysis was applied to single words, sentences or longer paragraphs, or to exchanges between focus group respondents.

Table 1. Extract of a priori and open codes

\begin{tabular}{|c|c|}
\hline A priori codes & Open codes \\
\hline Purpose & $\begin{array}{ll}\text { - } & \text { Purpose: buy-in } \\
\text { - } & \text { Purpose: compliance }\end{array}$ \\
\hline Practice & $\begin{array}{ll}\text { - } & \text { Practice: introduce contractor } \\
\text { - } & \text { Practice: identify representatives }\end{array}$ \\
\hline Constraints & $\begin{array}{l}\text { - Constraints: institutional } \\
\text { - } \text { Constraints: trust }\end{array}$ \\
\hline
\end{tabular}


Hundreds of codes were identified, of which 62 related to practices. Thematic axial coding was then used to explore possible themes and relations between codes. In this process, the data pertaining to officials' practices clearly resonated with the three practices identified in the literature. The data analysis was therefore iterative and abductive. This process was supplemented with three follow-up interviews, peer examination of the coding process, as well as 'member-checking' (Krefting 1991) of preliminary findings with select officials.

Given the focus on officials' experiences, the article excludes primary data on the experiences of political leaders, citizens and communities. Although this limits the analysis, it is intended to fill a gap in both participation and public leadership literatures. The former tends to focus on citizen and community experiences of participation (Tapscott and Thompson 2013), whilst the latter tends to focus on political leaders (Hartley and Benington 2011). This article therefore aims to contribute to public leadership research by focusing on the administrative domain.

\section{Findings and discussion}

Applying the framework of the three leadership practices discussed above, in this section we explore general trends and offer specific examples of how officials exercise leadership within participation at the project level. We find officials mobilize communities through formal advertising efforts, through the assistance of ward councillors and local leaders, with particular challenges in establishing project steering committees. In navigating relations, our research shows how employment and contract issues influence participation, with officials having to navigate local community boundaries as well as community-contractor relations. With regard to framing agendas, officials employ various tactics within project processes, and frame their efforts as both 'neutral' and 'making a change'. Based on these findings, we suggest the three practices 
emerge out of the interplay between, on the one hand, existing policies, formal participatory mechanisms and governance systems, and on the other, the limitations of these structures in accommodating local community dynamics. It is within this gap that officials adapt their practices and may be said to lead participatory processes.

\section{Mobilizing communities}

Mobilizing communities for participation in the South African local context involves both reach (engaging the broader community) and selection (identifying and convening local representatives). In their study of participation in the delivery of infrastructure projects, Thompson et al. (2018) identified numerous shortcomings in the way officials identify local representatives. We highlight two ways that officials mobilize communities, and examine the role of the project steering committee as a key structure for community representation in projects.

\section{Advertising through prescribed procedures and formal platforms}

Most officials' mobilization efforts begin with the requirements set out in national policy and municipal guidelines, which require advertising opportunities to engage or attend public meetings in local newspapers, on radio and in libraries. Although officials generally comply, many perceive these requirements as insufficient for providing information, and ineffective for ensuring adequate inclusion, especially of poor communities. For some, such communication efforts reflect the dominant compliance mind-set within the municipality, where many 'just advertise and go through the motions' (Interview F). When implementing specific projects, however, officials also use alternative strategies to mobilize communities, such as engaging ward councillors and local community leaders. These practices appear to emerge informally based on their knowledge and assessments of the local context (Crosby and Bryson 2005), as well 
as their relations with other actors.

\section{Mobilizing through ward councillors and community leadership structures}

To bring communities into project processes, officials first engage ward councillors as the municipality's formal political representatives. Although this is not legally required, it has developed into a fairly established practice. Councillors assist officials by identifying community leadership structures in an area, advising as to the best method for advertising a meeting, or even organizing and chairing meetings. In this regard, their involvement can be useful to 'bring a crowd' and secure community buy-in for a project (Focus group K). Councillors may also refuse to support a project, however, and act as gatekeepers or politicize project meetings. In one example, a ward councillor rejected a proposed housing upgrade, claiming 'the community' was not interested. When an official involved in the project visited residents door-to-door, many were reportedly interested and the project continued (Interview E).

Regardless of the involvement of councillors, officials believed working through community organisations and local leaders is crucial to secure permission to enter an area and to gain community buy-in. Informal settlements in particular tend to operate via organized community structures (Drivdal 2016), in the form of street committees or resident committees, community development forums, or broader organisations such as the South African National Civic Organisation (SANCO). Knowing and deciding who to work with can be difficult, however, with officials relying on a municipal database of registered organisations, their personal knowledge, and the suggestions of other officials and councillors. There may also be multiple organisations and informal leaders who claim to represent a particular area or interest. Officials detailed experiences where they had to actively search for leaders, manage gatekeeping between different factions, and were called out for accidentally excluding people. 
Mobilizing through ward councillors and community leaders suggests officials' practices involve a process of selection, as well as reliance on the local agency and power of others. In addressing the inadequacies of formal policies and structures, like the municipal database, the informal relationships officials have built with others in the municipality becomes a source of information and influence for deciding how to proceed. But this also raises questions regarding officials' ability to ensure inclusive and legitimate representation in projects. This issue especially comes to the fore in project steering committees.

\section{Convening project steering committees}

A Project Steering Committees (PSC) is the main structure for communities to have a voice in project decisions, and important mobilization work occurs through PSCs. It usually comprises ten to fifteen people who meet regularly, especially in the planning phase of a project to give inputs into designs and proposals (e.g. on housing layouts or public park amenities). These are advisory structures, however, and the municipality makes the final decisions. Composition of the PSC influences its representativeness, and thus the legitimacy of the structure and process as a whole. Who gets a seat on the committee can therefore be contentious. Whilst some departments follow internal guidelines for electing and structuring PSCs, it can also be up to the project leader to decide the process. In some cases, communities nominate representatives in a public meeting, or community leaders may do so in a smaller meeting with officials.

Officials' roles in the establishment of PSCs can vary. As project leaders, they can identify a particular stakeholder as a key beneficiary to have on the committee (whether from a specific sector or organisation). They also need to ensure adequate representation across the relevant communities and interest groupings. This, some explained, entails preventing gatekeeping by being attuned to the discursive tactics used 
in meetings, especially when not all leaders or organisations are present. At the same time, however, officials describe themselves as neutral in the process, and make efforts to accommodate any local organisations and individuals who claim to be legitimate representatives.

The complexities of ensuring appropriate representation on a PSC whilst remaining 'neutral' is illustrated in the experience of an official who inherited a project that had run into severe delays. The purpose of the project was to upgrade an informal settlement situated within a relatively well-developed ward. The existing PSC included representatives from the settlement as well as ratepayers' associations. The latter had used the PSC to stall the project in hopes of having the settlement removed altogether. Noticing there were only two representatives from the informal settlement on the PSC, the new project leader decided to re-establish the PSC, and held additional public meetings in the informal settlement to increase their number of representatives. The project leader thus influenced the composition of the PSC in order to balance the power between different interest groups.

This example illustrates the important power balancing work expected of public leaders for successful collaboration (Page 2010; Van Wart 2013). But it also suggests officials' practices are not necessarily neutral, and their mobilization work involves consideration of project goals. Alongside their efforts to adapt to local contexts, what also seems to drive officials' decisions and actions is the mandate to deliver services efficiently and effectively, which operates as a kind of first-order objective. Officials will therefore work with a councillor or not based on whether they believe the councillor will be supportive of the project. They may accommodate communities regarding the size and scope of representation, but they also intervene to better mobilize specific communities to ensure project success. Whilst it is up to the individual official 
to assess and respond to local community dynamics (suggesting an exercise of individual leader agency), this can also be explained as an effort to implement a particular project in a particular way, in accordance with their service delivery mandate.

\section{Navigating relations}

The second practice involves how officials navigate relations between different stakeholders. In this context, the municipality's reliance on outsourcing to deliver services means projects and participatory processes have become central mechanisms for individuals to access employment opportunities, and for local companies to gain sub-contracting work. This has also meant employment and contract allocations can inform community agendas in participation, and shape relations between community participants, and between communities and contractors. Officials navigate these relations in two key ways: by navigating (and responding to) local demands and boundaries; and by controlling interactions between communities and contractors. As with mobilizing, similar tensions between neutrality and project delivery are evident in the way officials navigate pressures around employment, where neutrality is essential, yet local dynamics may demand some level of 'intervention' in order to ensure project delivery.

\section{Navigating local demands and boundaries}

Although the municipality has formal mechanisms in place to allocate employment opportunities in government projects, officials reported numerous challenges to this system. For instance, the municipality provides a 'job-seekers database' that randomly selects people for short-term work. Yet officials raised concerns about its reliability, suggesting it is vulnerable to manipulation and circumvention through local patronage networks. The database also selects people within a sub-council area, but projects are 
often more localized. Employing workers in an area that do not also reside in that area has become a major issue. Formal demarcations between areas are also geopolitical spaces that do not map neatly onto the dynamic, socially constructed and 'lived boundaries' of communities. It is therefore up to officials to respond to these limits and adapt to local contexts. This means that, as one official explained, 'we have in some communities a catch-22 where you cannot follow a sub-council process, but you have to. And then you have to mitigate the fall-out in the community' (Focus group G).

Officials recounted numerous occasions where people do not follow municipal procedures but rather disrupt projects and services to demand employment or subcontracting opportunities. Challenges especially arise where there are local factions and gangs that claim control over specific territories and government contracts. In reflecting on these experiences, officials expressed a sense of resignation about the situation, arguing that, given the socio-economic conditions of communities, 'it's never going to go away' (Focus group G). As one official summarized, disruptions are such a common occurrence that, 'when it happens now you don't even worry about it, it's part of the process' (Focus group D).

In this context, officials cannot rely on the database to navigate relations. In one example, a relatively small utilities project with opportunities for short-term employment was earmarked for an area with a number of gangs. For the officials in charge, it was 'immaterial who you take off that database [because] you now need to screen them: where they stay, and who are they? Are they neutral to the community, or are they involved in the organisation?' (Focus group H). Ultimately, the officials had to find ways to accommodate the local dynamics in order to deliver the project. As with mobilizing, how officials address these challenges illustrate leader agency, rooted in officials' knowledge and relations with others. At the same time, the interview data 
made clear that efforts to address (and even accommodate) employment and contract issues are largely driven by the need to prevent vandalism and project disruption.

\section{Navigating between communities and contractors}

Being aware of employment and sub-contracting issues is an important component of officials' work, as indicated above. And as with mobilizing, there are limits to the formal mechanisms established for this purpose. Officials must therefore navigate the conflicts and competing interests that emerge. Within participation, officials try to manage and control relations in an effort to prevent such issues arising in the first place.

First and foremost, officials structure the introduction of contractors to communities, and try to control meetings and interactions between them in order to prevent unmediated conversations and the establishment of close relations. This is driven by the suspicion that, 'if they start dealing with the contractor, then they start manipulating the contractor' (Focus group K). Direct (and unmediated) interactions could allow leaders to influence who gets employed, potentially securing work for 'their brothers and sisters' (Interview F). Procedurally, then, officials try to ensure contractors are formally introduced to the project steering committee at a specific meeting, and to control the relationship thereafter in order to 'protect the contractor' from undue influence (Focus group K).

These experiences show how the use of outsourcing as a primary service delivery mechanism shapes the relation between the municipality and its citizenry, making employment and community-contractor relations more prominent within participation. This also impacts how officials navigate relations. Rather than weaving together interests and identities (Mandell and Keast 2009; Ospina and Foldy 2010), the practice of navigating relations in this context entails being aware of where and when to prevent the formation of relations. The ways in which they do so - by controlling when 
meetings happen - suggest officials rely on their positional power, provided through the municipality, to do so.

\section{Framing agendas}

The final practice we explored was framing agendas. In South African local government, formal agenda framing is purported to take place in the prioritisation of projects (as part of municipal-wide development planning and resource allocations), as well as in decision-making within specific projects. Although the development plan produces the 'blueprint' for what the municipality does over a five year period, there were concerns about how participation happens at this level, how inputs are taken into account, and whether the plan actually addresses people's concerns.

At the project level, officials use various micro-tactics to direct discussions and shape project agendas. They also perform specific discursive work that frames the participation agenda, which is evident in their claims to neutrality and references to the 'making a change'. Again, we suggest these practices illustrate the role of officials in adapting policy prescriptions and pursuing project delivery goals, but also the limits of their leadership influence.

\section{Micro-tactics to frame project agendas}

As with their mobilizing practices, officials are guided by policies and plans that establish government priorities and that underpin project selection, design and implementation. In pursuit of the broader policy agenda, officials use a number of micro-tactics to frame participation at the project level. These include, for instance: involving political leaders to support an initiative; using physical models (e.g. of park layouts or to show water leaks) as a way of presenting a problem; and enlisting external organisations and facilitators to mediate between the municipality and communities, and 
to present a 'neutral' view of a problem.

Agenda framing also occurs through deliberations over project options, often in project steering committees. In such discussions, project plans are rarely entirely 'open'. Officials may 'coach' the PSC in particular ways, and use various 'structuring tactics' to facilitate discussions or build relations in order to move towards project completion. One official, for instance, delegates responsibility to community leaders to chair committee meetings. Another uses the PSC's Terms of Reference, as well as any relevant municipal policies, to intervene when disagreements between community leaders become overly tense. In these ways, officials may be said to direct the agenda through various structuring tactics and rely on relational and policy resources to do so. It is beyond the scope of this paper to unpack these various micro-tactics further, suffice to say these resonate with the kinds of tactics identified by Vangen and Huxham (2003) that project leaders may use to manoeuvre people towards a specific goal, but which they also deem potentially manipulative.

\section{Claiming neutrality and transformation}

Woven into these micro-tactics, as well as in their project and service delivery work more generally, officials seem to frame agendas through their talk. They do so primarily through claims to political neutrality and references to 'making a change'. Some claim neutrality, for instance, in relation to project objectives, as well as the selection of representatives onto participatory structures (as discussed above). Such claims reflect an active effort to depoliticize project plans and engagements. They distinguish themselves from politicians, believing this is important for people to 'actually understand what you're saying' and not 'see you as a threat', and to understand 'I'm here to make a change for you' (Focus group K). However, that officials sometimes engage local councillors in order to use their political backing to secure community buy-in also 
suggests these can be strategic choices or intentional acts of agenda framing.

Further, officials' narratives regarding their positions as neutral administrators, and their work as 'making a change' for communities, seems to overlook the possibility of different visions and options for change. This suggests participatory processes do not necessarily enable communities to really critique proposed project plans, to introduce and consider alternatives, and thus to contribute to defining the nature of such change. It is therefore less about deliberations to grasp different perspectives and transform understanding of the problem (Ansell and Gash 2007; Chrislip and Larson 1994; Doberstein 2016), than it is about deliberate contextualizing towards a specific goal (Corvellec and Risberg 2007). But project delivery goals must also be understood in terms of broader governance trends, in particular the drive towards efficiency and budget spend under the auspices of New Public Management (NPM) (Harrison 2006). This context informs agenda framing and decision-making, even and especially in community engagements at the project level, which was confirmed across the interviews and focus groups of this research. But such measures sit in tension with the time, flexibility, and risk-taking that meaningful engagement requires, and undermines the substantive quality and depth thereof (Winkler 2011).

Officials' narratives can therefore be understood as reflections of a particular interpretation of both communities' service delivery needs and the nature of the municipality's response, namely that these are technical problems and inefficiencies that can be addressed through a technocratic managerialist approach. But this further delimits the scope of participation. Although there were examples of communities making inputs into project design decisions (e.g. housing typologies, park amenities), the final decision-making occurs elsewhere. Such projects also only come to communities following budget allocations decided in council. Officials may lead a local 
engagement processes towards shared understanding of issues and solutions (Crosby and Bryson 2010), but this remains subject to already established priorities and measures of success. In the next section, we reflect on the implications of these findings for the understanding of public leadership, before offering some practical recommendations.

\section{Implications for public leadership}

Our study explored the experiences of municipal officials in leading participation in informal settlement communities in South Africa. Our aim was to understand their leadership practices as well as what informs their practices. On the whole, our research confirms the relevance of the three practices as a framework for leadership in participatory/collaborative processes. In fact, officials in this study were involved in a variety of service delivery processes and forms of engagement, and yet their varied practices found expression within this framework. One possible conclusion to draw from this is that this set of practices pinpoint crucial components or 'moments' in participation that influence the shape and direction of engagements.

Further, the challenges of collaboration are widely acknowledged in the literature (Torfing et al. 2019; Vangen et al. 2015), in particular that of facilitating the process in a 'shared power world' (Crosby and Bryson 2005). In theory, public leadership in such contexts is expected to involve more relational and lateral forms of engagement towards a common purpose, rather than vertical leadership originating in the formal positional authority of the leader (Torfing et al. 2019). However, in line with the work of Currie et al. (2011) and Waugh and Streib (2006), we suggest 'collaboration' between municipal officials and communities (particularly informal settlement communities in developing country contexts) remains embedded in the formal, structural power of the municipality and officials within it. Of course, 
communities and community leaders also exhibit agency in the ways they navigate municipal processes in order to get onto a PSC, get access to contracts and job opportunities, and influence project agendas. But leadership is not equally distributed (Currie et al. 2011), and power and influence remains concentrated in the role of officials, who can be selective in how they mobilize representatives, how they utilize existing structures (e.g. the PSC, policies, databases, councillors) to organize meetings and agendas, and how they control interactions between stakeholders within the process.

Further, this interplay between officials and communities, and the unequal influence of officials in the process, remains embedded in the municipal governance system that constrains their space to manoeuvre (Connelly 2007). Officials' leadership practices may therefore be said to operate as conduits for government service delivery agendas. In their study of emergency management in the U.S., for example, Waugh and Streib (2006) make a similar claim, explaining how the federal government continues to 'command and control', via legal and normative structures, how officials lead 'on the ground'. Our study shows how specific aspects of national policy around participation and service delivery manifest at the local level in the way officials lead and manage community participation. This informs, for instance, which stakeholders are brought on board, as well as how relations and power conflicts between them are managed.

These constraints on officials' practices are not necessarily indicative of a leadership failure, however, or of the absence of leadership roles or work by officials in participation (Waugh and Straub 2006). Rather, officials' efforts to adapt to local contexts suggest formal policies and structures are themselves inadequate, as the complexities of community participation cannot simply be 'managed' from above. This makes it the task of officials who must implement policy, to resolve the tension between the mandate to engage (and giving communities an actual voice in decision-making) 
and the mandate to deliver. It is precisely here where officials' leadership agency comes to the fore. And yet, officials are still structurally limited to mitigating power relations and competing interests at the local level only (i.e. within the scope of a singular project).

These findings resonate with social constructionist approaches that theorize leadership influence as the interplay of structure or context, and individual practices and capabilities (Crosby and Bryson 2005, Huxham and Vangen 2005, Sullivan et al. 2012). In this way, individual leader practices provide an entry point for a multi-level analysis to explore the influence of broader processes, structures and contextual factors. Although this study provides only a limited analysis at this level, a potential area for future research is to distinguish between 'micro' level changes that occur within pre-set project boundaries, and changes in broader development trajectories and at the level of political economy. This line of inquiry could open up questions regarding the theorisation of public leadership in collaboration as a one of 'power-sharing' towards a 'shared vision', as a way to assess both the source and scope of leadership at different levels.

\section{Conclusions and recommendations}

As collaboration becomes an increasingly common form of governance and service delivery (Ansell and Gash 2007), it is often government officials who must take on the role of leading collaborative engagements. This article has explored how local officials in a South African municipality take up this leadership role to engage informal settlement communities. Employing a social constructionist approach, we considered officials' practices in mobilizing communities and local representatives, navigating relations between communities and contractors, and framing agendas within project 
processes. The research shows how officials' practices emerge at the intersection between formal government structures (i.e. policies, participatory mechanisms, service delivery models) and local community realities and dynamics. Although they exercise leadership agency in adapting policy requirements within project engagements, officials remain constrained insofar as their practices are driven primarily by project delivery goals and broader governance objectives.

This research also has implications for practice, both for municipalities and public administration in South Africa more broadly. First, formally required forms of 'advertising' (i.e. through libraries, radios and newspapers) should be reviewed so that resources could be made available for more effective use of a variety of media. Providing multiple avenues and easier ways for community organisations and representatives to be identified or make themselves known to government could also enable more reliable means for mobilizing stakeholders.

Second, there are structural aspects that could be improved or changed in order to better support the ideals of engagement. These include distinguishing participatory processes from employment and contract allocation decisions for public projects, in order to disconnect spaces to discuss project plans from processes of allocating work. Incorporating qualitative performance management indicators focused on community engagement could also go a long way to support participatory governance ideals in order to balance quantitative delivery targets engineered for efficiency and cost recovery.

Finally, the limited scope for community input during project implementation points to the critical importance of ensuring effective engagement in broader governance processes around long-term development planning, prioritisation and budgeting. In this regard, we agree with Sørensen and Torfing (2019) that it is important 
to deepen citizen engagements in earlier processes of policy-making. Our study also illuminates the risk of focusing only on formal, government-led structures or spaces of collaboration, or what Cornwall (2008) describes as 'invited spaces', insofar as these remain embedded in predetermined objectives reflecting political agendas and governance systems. Rather, acknowledging and being responsive to 'invented spaces' (Cornwall 2008) led by community and civic actors can also enable more inclusive agendas, as long as the priorities identified in such spaces find footing in government decision-making.

\section{Funding details}

This research was supported by the Human Sciences Research Council and South African National Treasury under Grant [RFP 13/2012] awarded through the Development Bank of Southern Africa; and a University of Pretoria Postgraduate Bursary.

\section{References}

Alvesson, M. and Spicer, A. 2012. Critical leadership studies: The case for critical performativity. Human Relations, 65(3): 367-390.

Ansell, C. and Gash, A. 2007. Collaborative governance in theory and practice. Journal of Public Administration Research and Theory, 18(4): 543-571.

Armistead, C., Pettigrew, P. and Aves, S. 2007. Exploring leadership in multi-sectoral partnerships. Leadership, 3(2): 211-230.

Berg, B. 2001. Qualitative research methods for the social sciences. $4^{\text {th }}$ ed. Boston: Allyn and Bacon.

Bono, J., Shen, W. and Snyder, M. 2010. Fostering integrative community leadership. The Leadership Quarterly, 21(2): 324-335.

Bryman, A. 2004. Qualitative research on leadership: A critical but appreciative review. The Leadership Quarterly, 15(6): 729-769. 
Bussu, S. and Galanti, M.T. 2018. Facilitating coproduction: The role of leadership in coproduction initiatives in the UK. Policy and Society, 37(3): 347-367.

Carroll, B., Levy, L. and Richmond, D. 2008. Leadership as practice: Challenging the competency paradigm. Leadership, 4(4): 363-379.

Cepiku, D. and Mastrodascio, M. 2019. Leadership behaviours in local government networks: an empirical replication study. Public Management Review, DOI: 10.1080/14719037.2019.1679233.

Chapman, C., Getha-Taylor, H., Holmes, M.H., Jacobson, W.S., Morse, R.S. and Sowa, J.E. 2015. How public service leadership is studied: an examination of a quarter century of scholarship. Public Administration, 94(1): 111-128.

Chrislip, D. and Larson, C. 1994. Collaborative leadership: How citizens and civic leaders can make a difference. San Francisco: Jossey-Bass.

Collinson, D. 2014. Dichotomies, Dialectics and dilemmas: New directions for critical leadership studies? Leadership, 10(1): 36-55.

Connelly, D. 2007. Leadership in the collaborative interorganizational domain. International Journal of Public Administration, 30(11): 1231-1262.

Corvellec, H. and Risberg, A. 2007. Sensegiving as mise-en-sens - the case of wind power development. Scandinavian Journal of Management, 23(3): 306-326.

Crevani, L., Lindgren, M., and Packendorff, J. 2010. Leadership, not leaders: On the study of leadership as practices and interactions. Scandinavian Journal of Management, 26(1): 77-86.

Crosby, B. and Bryson, J. 2005. A leadership framework for cross-sector collaboration. Public Management Review, 7(2): 177-201.

Crosby, B. and Bryson, J. 2010. Integrative leadership and the creation and maintenance of cross-sector collaborations. The Leadership Quarterly, 21(2): 211-230. 
Currie, G., Grubnic, S. and Hodges, R. 2011. Leadership in public services networks: Antecedents, process and outcome. Public Administration, 89(2): 242-264.

Dacombe, R. 2011. Who leads? Councillor-officer relations in local government overview and scrutiny committees in England and Wales. International Journal of Leadership in Public Services, 7(3): 218-228.

Doberstein, C. 2016. Designing collaborative governance decision-making in search of a 'collaborative advantage'. Public Management Review, 18(6): 819-841.

Drath, W.H., McCauley, C.D., Palus, C.J., Van Velsor, E., O'Connor, P.M.G. and McGuire, J.B. 2008. Direction, alignment, commitment: Toward a more integrative ontology of leadership. The Leadership Quarterly, 19(6): 635-653.

Drivdal, L. 2016. Community leadership in urban informal neighbourhoods: Micropolitics and micro-administration in informal settlements in Cape Town. Urban Forum, 27(3): 275-295.

Fairhurst, G. and Grant, D. 2010. The social construction of leadership: A sailing guide. Management Communication Quarterly, 24(2): 171-210.

Feldman, M., Khademian, A., Ingram, H. and Schneider, A. 2006. Ways of knowing and inclusive management practices. Public Administration Review, 66(s1): 89-99. Fung, A. and Wright, E.O. 2001. Deepening democracy: Innovations in empowered participatory governance. Politics \& Society, 29(1): 5-41.

Harrison, P. 2006. Integrated development plans and third way politics. In: Pillay, U., Tomlinson, R. and du Toit, J. (eds.) Democracy and delivery: urban policy in South Africa. Cape Town: HSRC. Pp. 186-207.

Hartley, J. and Benington, J. 2011. Political leadership. In: Bryman, A., Collinson, D., Grint, K., Jackson, B. and Uhl-Bien, M. (eds.) The SAGE handbook of leadership. London: SAGE. Pp. 203-214. 
Heller, P. 2001. Moving the state: The politics of democratic decentralisation in Kerala, South Africa, and Porto Alegre. Politics \& Society, 29(1): 131-163.

Hosking, D.M. 2011. Moving relationality: Meditations on a relational approach to leadership. In: Bryman, A., Collinson, D., Grint, K., Jackson, B. and Uhl-Bien, M. The SAGE handbook of leadership. London: SAGE. Pp. 455-467.

HDA (Housing Development Agency). 2012. South Africa: Informal settlements status. Research Report. Johannesburg: Housing Development Agency. Hsieh, J.Y. and Liou, K.T. 2018. Collaborative leadership and organizational performance: Assessing the structural relation in a public service agency. Review of Public Personnel Administration, 38(1): 83-109.

Huxham, C. and Vangen, S. 2005. Managing to collaborate: The theory and practice of collaborative advantage. London: Routledge.

Kellis, D.S . and Ran, B. 2013. Modern leadership principles for public administration: Time to move forward. Journal of Public Affairs, 13(1): 130-141.

Klag, M. and Langley, A. 2013. Approaching the conceptual leap in qualitative research. International Journal of Management Reviews, 15(2): 149-166.

Knights, D. and Willmott, H. 1992. Conceptualising leadership processes: A study of senior managers in a financial services company. Journal of Management Studies, 29(6): 761-782.

Krefting, L. 1991. Rigor in qualitative research: The assessment of trustworthiness. American Journal of Occupational Therapy, 45(3): 214-222.

Lawler, J. 2008. Individualization and public sector leadership. Public Administration, 86(1): 21-34. 
Lemanski, C. 2017. Unequal citizenship in unequal cities: Participatory urban governance in contemporary South Africa. International Development Planning Review, 39(1): 15-35.

Mandell, M. and Keast, R. 2009. A new look at leadership in collaborative networks: process catalysts. In: Raffel, J., Leisink, P. and Middlebrooks, A. (eds.) Public sector leadership: international challenges and perspectives. Cheltenham, UK: Edward Elgar. Pp. 163-178.

Miles, M., Huberman, A.M. and Saldaña, J. 2014. Qualitative data analysis: A methods sourcebook. $3^{\text {rd }}$ edition. Thousand Oaks: SAGE.

Miraftab, F. and Wills, S. 2005. Insurgency and spaces of active citizenship: The story of Western Cape Anti-eviction Campaign in South Africa. Journal of Planning Education and Research, 25(2): 200-217.

Morse, R. 2010. Integrative public leadership: Catalyzing collaboration to create public value. The Leadership Quarterly, 21(2): 231-245.

Oldfield, S. 2008. Participatory mechanisms and community politics: Building consensus and conflict. In: van Donk, M., Swilling, M., Pieterse, E. and Parnell, S. (eds.) Consolidating developmental local government: lessons from the South African Experience. Cape Town: UCT Press. Pp. 487-500.

O'Leary, R. and Vij, N. 2012. Collaborative public management: Where have we been and where are we going? The American Review of Public Administration, 42(5): 507522.

Ollerenshaw, A., Murphy, A. and McDonald, K. 2017. Leading the way: the integral role of local government within a multisector partnership delivering a large infrastructure project in an Australian growth region. Local Government Studies, 43(2): 291-314. 
Orazi, D., Turrini, A. and Valotti, G. 2013. Public sector leadership: New perspectives for research and practice. International Review of Administrative Sciences, 79(3): 486504.

Ospina, S. 2017. Collective leadership and context in public administration: Bridging public leadership research and leadership studies. Public Administration Review, 77(2): $275-287$.

Ospina, S. and Foldy, E. 2010. Building bridges from the margins: The work of leadership in social change organizations. The Leadership Quarterly, 21(2): 292-307. Ospina, S. and Saz-Carranza, A. 2010. Paradox and collaboration in network management. Administration \& Society, 42(4): 404-440.

Page, S. 2010. Integrative leadership for collaborative governance: Civic engagement in Seattle. The Leadership Quarterly, 21(2): 246-263.

Raelin, J.A. 2016. Imagine there are no leaders: Reframing leadership as collaborative agency. Leadership, 12(2): 131-158.

Raffel, J., Leisink, P. and Middlebrooks, A. 2009. Introduction. In: Raffel, J., Leisink, P. and Middlebrooks, A. (eds.) Public sector leadership: International challenges and perspectives. Cheltenham, UK: Edward Elgar.

RSA (Republic of South Africa). 1996. Constitution of the Republic of South Africa. [Online] Available from: http://www.info.gov.za/documents/constitution/1996/a10896.pdf. [Accessed: 27 July 2011].

RSA (Republic of South Africa). 2000. Municipal Systems Act (MSA), Act 32 of 2000. [Online] Available from: http://www.info.gov.za/view/DownloadFileAction?id=68199. [Accessed: 25 July 2011].

Robins, S., Cornwall, A. and von Lieres, B. 2008. Rethinking 'citizenship' in the postcolony. Third World Quarterly, 29(6): 1069-1086. 
Sinwell, L. 2011. Is 'another world' really possible? Re-examining counter-hegemonic forces in post-apartheid South Africa. Review of African Political Economy, 38(127): $61-76$.

Smith, L. 2011. The limits to public participation in strengthening public accountability: A reflection on the 'Citizens' Voice' initiative in South Africa. Journal of Asian and African Studies, 46(5): 504-517.

Sørensen, E. and Torfing, J. 2019. Designing institutional platforms and arenas for interactive political leadership. Public Management Review, 21(10): 1443-1463. Sullivan, H., Williams, P. and Jeffares, S. 2012. Leadership for collaboration: Situated agency in practice. Public Management Review, 14(1): 41-66.

Tapscott, C. and Thompson, L. 2013. Between supply and demand: the limits to participatory development in South Africa. International Review of Administrative Sciences, 79(2): 368-385.

Torfing, J., Sørensen, E., and Røiseland, A. 2019. Transforming the public sector into an arena for co-creation: barriers, drivers, benefits, and ways forward. Administration \& Society, 51(5): 795-825.

Tourish, D. and Barge, K. 2010. An exchange of letters: What can a specifically social constructionist perspective bring to bear on what must be one of the most studied subjects in human history? Management Communication Quarterly, 24(2): 322-347. Turok, I. and Parnell, S. 2009. Reshaping cities, rebuilding nations: The role of national urban policies. Urban Forum, 20(2): 157-174.

Uhl-Bien, M. 2006. Relational leadership theory: Exploring the social processes of leadership and organizing. The Leadership Quarterly, 17(6): 654-676.

Uster, A., Beeri, I. and Vashdi, D. 2018. Don’t push too hard. Examining the managerial behaviours of local authorities in collaborative networks with nonprofit 
organisations. Local Government Studies, 34(2): 1-22.

doi:10.1080/03003930.2018.1533820.

Vangen, S., Hayes, J. and Cornforth, C. 2015. Governing Cross-Sector, Inter-

Organizational Collaborations. Public Management Review, 17(9): 1237-1260.

Vangen, S. and Huxham, C. 2003. Enacting leadership for collaborative advantage:

Dilemmas of ideology and pragmatism in the activities of partnership managers. British Journal of Management, 14(s1): S61-S76.

Van Wart, M. 2013. Administrative leadership theory: a reassessment after 10 years.

Public Administration, 91(3): 521-543.

Vogel, R. and Masal, D. 2015. Public leadership: a review of the literature and framework for future research. Public Management Review, 17(8): 1165-1189. von Schnitzler, A. 2008. Citizenship prepaid: Water, calculability, and techno-politics in South Africa. Journal of Southern African Studies, 34(4): 899-917.

Wallace, M., O'Reilly, D., Morris, J. and Deem, R. 2011. Public Service Leaders as 'Change Agents' - for Whom? Public Management Review, 13(1): 65-93.

Waugh, W.L. and Streib, G. 2006. Collaboration and leadership for effective emergency management. Public Administration Review, 66(s1): 131-140.

Winkler, T. 2011. Retracking Johannesburg: Spaces for participation and policy making. Journal of Planning Education and Research, 31(3):258-271. 